\title{
The Coupling of Protonation and Reduction in Proteins with Multiple Redox Centers: Theory, Computational Method, and Application to Cytochrome $c_{3}$
}

\author{
G. Matthias Ullmann* \\ Department of Molecular Biology, The Scripps Research Institute, 10550 N. Torrey Pines Rd., TPC-15, \\ La Jolla, California 92037
}

Received: February 23, 2000; In Final Form: May 2, 2000

\begin{abstract}
The coupling of protonation and reduction is crucial in many biological charge transfer reactions and is known as redox Bohr effect. It is caused by electrostatic interactions between protonatable and redox-active groups. In this study, I describe a method to calculate protonation and oxidation probabilities depending on the solution $\mathrm{pH}$ and redox potential. The energetic calculations are based on the linearized Poisson-Boltzmann equation. The actual calculation of the oxidation and protonation probabilities is done with a hybrid statistical mechanics/ Tanford-Roxby approach. The method is applied to cytochrome $c_{3}$, a small protein that binds four hemes. The protein is known for coupling a protonation to the reduction reactions. The propionate D of heme I shows the strongest redox potential dependence of its protonation probability and is thus most likely responsible for the redox Bohr effect. The computational results agree well with experimental data. Because of the interactions between the many titratable groups in proteins, titration curves often deviate significantly from the sigmoidal shape of Henderson-Hasselbalch or Nernst titration curves. This deviation requires the definition of $\mathrm{p} K_{\mathrm{a}}$ and $E^{\circ}$ values that depend on the $\mathrm{pH}$ and solution redox potential. The definitions of $\mathrm{p} K_{\mathrm{a}}$ and $E^{\circ}$ values provided in this study are appropriate for discussing the energetics of protonation and redox reactions throughout the whole investigated $\mathrm{pH}$ and solution redox potential range.
\end{abstract}

\section{Introduction}

The coupling between electron and proton transfer plays a crucial role in many biologically important reactions. Often this coupling is of electrostatic nature. A proton neutralizes the negative charge of an electron. The reduction of a redox-active center raises the $\mathrm{p} K_{\mathrm{a}}$ value of an adjacent protonatable group and makes it thus more likely that a proton can neutralize the negative charge of the electron. Such a coupling can be observed in the photosynthetic reaction center, cytochrome $c_{3}$, and probably in most electron transfer processes that are coupled to a proton transfer. This phenomenon is also known as the redox Bohr-effect. Other mechanisms use an electrochemical coupling, i.e., the redox-active group and the protonatable group are identical. Quinones couple, for instance, electron transfer and proton-transfer reactions using such a mechanism. Often different mechanisms are combined in one protein to couple the proton and electron transfer processes. ${ }^{1,2}$

Although the titration behavior of proteins ${ }^{3-14}$ and the influence of mutations on midpoint potentials ${ }^{15,16}$ are intensively investigated theoretically, only a few studies investigate the $\mathrm{pH}$ dependence of midpoint potentials. ${ }^{17-22}$ In most studies, the influence of the redox state on the protonation pattern is investigated. The influence of solution redox potential and $\mathrm{pH}$ on oxidation and protonation probabilities of the redox-active and protonatable groups is, however, usually not considered.

Cytochrome $c_{3}$ (depicted in Figure 1) is a part of the sulfatereducing electron-transfer chain in bacteria that use $\mathrm{H}_{2}$ as an energy source. Cytochrome $c_{3}$ can be found in the periplasm of these bacteria where the $\mathrm{pH}$ is about neutral. This tetraheme cytochrome transfers electrons from hydrogenase to sulfate-

\footnotetext{
*E-mail: ullmann@scripps.edu. Fax: 858-784-8896.
}

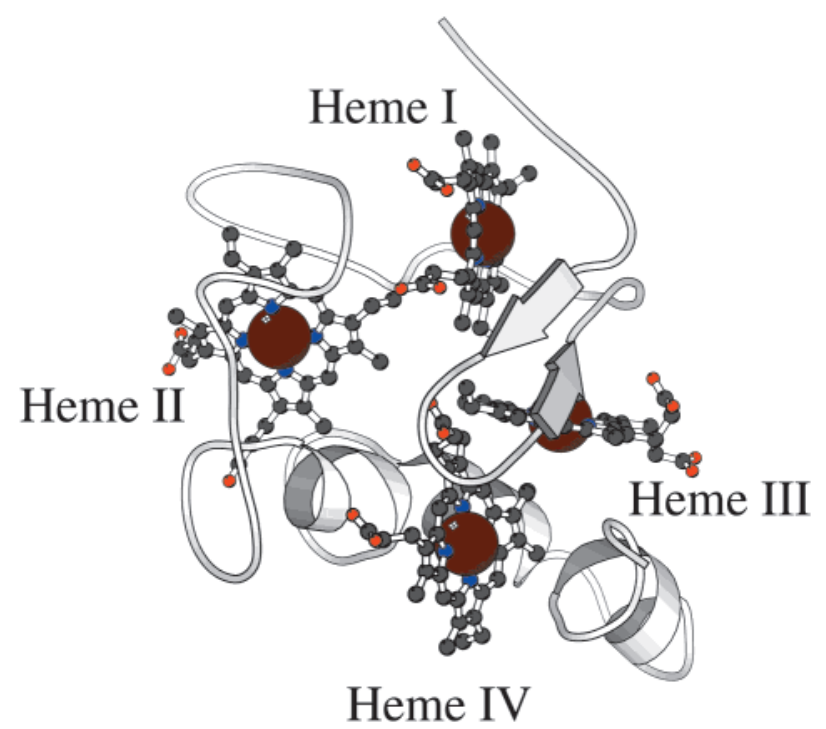

Figure 1. Structure of cytochrome $c_{3}$ from Desulfovibrio vulgaris Miyazaki. The protein binds four hemes. The numbering of the hemes used in this study is indicated in the picture.

reducing enzymes. Upon reduction of cytochrome $c_{3}$, protons bind to the protein (redox-Bohr effect). Despite its moderate size, cytochrome $c_{3}$ possesses more than 40 protonatable groups, of which eight are the heme propionates. All four hemes in cytochrome $c_{3}$ are $c$-type heme with two histidines coordinating to the iron. Although all four hemes are of the same chemical nature, their midpoint potentials differ. It is generally accepted that the protein environment is responsible for shifting the redox potential of prosthetic groups. The differences of the midpoint 
potentials are caused by different interactions with other charged and polar groups of the proteins and by different solvent accessibilities of the hemes. Because protonatable groups contribute also to the midpoint potential differences, the midpoint potentials of the hemes in cytochrome $c_{3}$ depend on $\mathrm{pH}$. Understanding of the $\mathrm{pH}$ dependence of midpoint potentials in cytochrome $c_{3}$ is important for the understanding of the coupling between protonation and reduction.

Due to the interaction between the heme groups, the redox titration behavior of individual hemes in cytochrome $c_{3}$ does not follow the Nernst equation. The interaction of the heme centers with titratable groups is the reason for the $\mathrm{pH}$ dependent redox potential. Its electrochemical complexity and moderate size make cytochrome $c_{3}$ a good model protein to study the electrostatic coupling of proton and electron transfer in molecular bioenergetic systems.

In this paper, I describe a method for calculating the protonation and oxidation probabilities in proteins with multiple protonatable and redox-active groups depending on $\mathrm{pH}$ and solution redox potentials. I use electrostatic calculations based on the Poisson-Boltzmann equation and a hybrid statistical mechanics/Tanford-Roxby method to compute protonation and oxidation probabilities. In the first part of the paper, I describe the theory and the method to calculate protonation and oxidation probabilities in proteins with many protonatable and redox active groups. In the second part, I apply the new method to calculate the coupling between protonation and reduction of cytochrome $c_{3}$ from Desulfovibrio vulgaris Miyazaki. The computation agrees well with experimental data, and groups which are involved in the redox-Bohr effect are identified.

\section{Theory and Methods}

Formulation of the Problem. Given is a system with $N$ protonatable groups and $K$ redox-active groups. The charge of the protein depends not only on $\mathrm{pH}$ but also on the solution redox potential. If one assumes that each titratable (protonatable or redox-active) group can exist in two states, protonated and deprotonated, or oxidized and reduced, the protein possesses $2^{N+K}$ different protonation and redox states. Each state of the protein can be described by a $(N+K)$-dimensional vector $\vec{x}$ specifying the protonation and redox state of the protein. The components $x_{\mu}$ of that vector $\vec{x}$ adopt either the value 1 or 0 , depending on whether the group $\mu$ is protonated (oxidized) or deprotonated (reduced).

The protonation or oxidation probability $\left\langle x_{\mu}\right\rangle$ of the group $\mu$ is given by a thermodynamic average over all possible protonation and redox states given by eq 1

$$
\left\langle x_{\mu}\right\rangle=\frac{\sum_{n=1}^{2^{N+K}} x_{\mu}^{n} \exp \left(-G_{n} / R T\right)}{\sum_{n=1}^{2^{N+K}} \exp \left(-G_{n} / R T\right)}
$$

where $x_{u}^{n}$ is 1 or 0 depending whether the group $\mu$ is protonated (oxidized) or not in state $n, G_{n}$ is the free energy of the protonation and redox state $n, R$ is the universal gas constant, and $T$ is the temperature. The probability of a particular protonation or redox substate involving more than one titratable group can be obtained analogously to eq 1 . From this probability, $\left\langle x_{\mu}\right\rangle$, it is possible to calculate the energetic parameters, such as the $\mathrm{p} K_{\mathrm{a}}$ value and midpoint potentials, as a function of the $\mathrm{pH}$ value and redox potential of the solution.

Description of Acid-Base and Redox Reactions. The protonation equilibrium of a single protonatable group can be described by eq 2 , where $K_{\mathrm{a}}$ is the equilibrium constant.

$$
\mathrm{HA} \stackrel{K_{\mathrm{a}}}{\rightleftharpoons} \mathrm{A}^{-}+\mathrm{H}^{+} \quad K_{\mathrm{a}}=\frac{\left[\mathrm{A}^{-}\right]\left[\mathrm{H}^{+}\right]}{[\mathrm{HA}]}
$$

The $\mathrm{pH}$ of the solution and the $\mathrm{p} K_{\mathrm{a}}$ of an acid are respectively defined as the negative decadic logarithm of the hydrogen ion concentration $\left(\mathrm{pH}=-\lg \left[\mathrm{H}^{+}\right]\right)$and the $K_{\mathrm{a}}$ value $\left(\mathrm{p} K_{\mathrm{a}}=-\lg \right.$ $K_{\mathrm{a}}$ ). With these definitions one obtains the HendersonHasselbalch equation (eq 3) from eq 2.

$$
\mathrm{pH}=\mathrm{p} K_{\mathrm{a}}+\lg \frac{\left[\mathrm{A}^{-}\right]}{[\mathrm{HA}]}
$$

The $\mathrm{p} K_{\mathrm{a}}$ value relates to the standard reaction free energy $G_{\text {prot }}^{\circ}$ as given by $G_{\mathrm{prot}}^{\circ}=-R T \ln 10 \mathrm{p} K_{\mathrm{a}}$. The probability $\langle x\rangle$ that the acid HA is protonated is given by $\langle x\rangle=[\mathrm{HA}] /\left([\mathrm{HA}]+\left[\mathrm{A}^{-}\right]\right)$. With this definition, and eqs 2 and 3 one obtains

$$
\langle x\rangle=\frac{\exp \left(-\ln 10\left(\mathrm{pH}-\mathrm{p} K_{\mathrm{a}}\right)\right)}{1+\exp \left(-\ln 10\left(\mathrm{pH}-\mathrm{p} K_{\mathrm{a}}\right)\right)}
$$

From eq 4 , one can read that the free energy $G_{\text {prot }}$ required to protonate a titratable group at a given $\mathrm{pH}$ and temperature is given by eq 5 .

$$
G_{\text {prot }}=R T \ln 10\left(\mathrm{pH}-\mathrm{p} K_{\mathrm{a}}\right)=-R T \ln \frac{\langle x\rangle}{1-\langle x\rangle}
$$

The description of a redox equilibrium is very similar to that of an acid-base equilibrium. The equilibrium between the redox couple $\mathrm{A}_{\mathrm{oX}} / \mathrm{A}_{\text {red }}^{-}$is defined in eq 6

$$
\mathrm{A}_{\mathrm{ox}}+\mathrm{e}^{-\stackrel{K_{\mathrm{ET}}}{\rightleftharpoons}} \mathrm{A}_{\text {red }}^{-} \quad K_{\mathrm{ET}}=\frac{\left[\mathrm{A}_{\text {red }}^{-}\right]}{\left[\mathrm{A}_{\mathrm{ox}}\right]\left[\mathrm{e}^{-}\right]}
$$

where $K_{\mathrm{ET}}$ is the equilibrium constant. Analogously to the $\mathrm{pH}$ and the $\mathrm{p} K_{\mathrm{a}}$ in the derivation of the Henderson-Hasselbalch equation (eq 3 ), one defines the solution redox potential $E$ and the midpoint potential $E^{\circ}$ of the redox couple $\mathrm{A}_{\text {ox }} / \mathrm{A}_{\text {red }}^{-}$as $E=$ $-R T / F \ln \left[\mathrm{e}^{-}\right]$and $E^{\circ}=R T / F \ln K_{\mathrm{ET}}$, respectively. Here, however, the natural logarithm rather than the decadic logarithm is used. With the factor $R T / F$, where $F$ is the Faraday constant, one obtains $E$ and $E^{\circ}$ in the unit Volt. The relation between $E^{\circ}$ and the standard reaction free energy $G_{\text {redox }}^{\circ}$ is given by $G_{\text {redox }}^{\circ}$ $=F E^{\circ}$. With these definitions and eq 6 one obtains the Nernst equation (eq 7) which is analogous to the HendersonHasselbalch equation (eq 3).

$$
E=E^{\circ}+\frac{R T}{F} \ln \frac{\left[\mathrm{A}_{\mathrm{ox}}\right]}{\left[\mathrm{A}_{\mathrm{red}}^{-}\right]}
$$

The probability $\langle x\rangle$ that a redox-active group is in its oxidized state is defined as $\langle x\rangle=\left[\mathrm{A}_{\mathrm{ox}}\right] /\left(\left[\mathrm{A}_{\text {red }}^{-}\right]+\left[\mathrm{A}_{\mathrm{ox}}\right]\right)$. In analogy to eq 4 , the relation between the probability $\langle x\rangle$, the solution redox potential $E$, and the midpoint potential $E^{\circ}$ is given by eq 8 .

$$
\langle x\rangle=\frac{\exp \left(\frac{F}{R T}\left(E-E^{\circ}\right)\right)}{1+\exp \left(\frac{F}{R T}\left(E-E^{\circ}\right)\right)}
$$


Consequently, the free energy $G_{\text {redox }}$ required to oxidize a redoxactive group at a given redox potential of the solution $E$ is given by eq 9 .

$$
G_{\text {redox }}=-F\left(E-E^{\circ}\right)=-R T \ln \frac{\langle x\rangle}{1-\langle x\rangle}
$$

Computation of the Protonation/Redox State Energy for a Protein. For the energy calculation of a particular protonation and redox state of the protein, the following energy terms are required: the $\mathrm{p} K_{\mathrm{a}}$ values of proper model compounds for the protonatable groups, the midpoint potential of a proper model compounds for the redox-active groups, the difference between the $\mathrm{p} K_{\mathrm{a}}$ value of the model compound and the $\mathrm{p} K_{\mathrm{a}}$ value of the protonatable group in the reference state of the protein, the difference between the midpoint potential of the model compound and the midpoint potential of the redox-active group in the reference state of the protein, the interaction between the protonatable groups, the interaction between the redox-active groups, and the interaction between the redox-active groups and the protonatable groups.

The intrinsic $\mathrm{p} K_{\mathrm{a}}$ values and intrinsic midpoint potentials are the $\mathrm{p} K_{\mathrm{a}}$ values and midpoint potentials the titratable groups would have if all other titratable groups in the protein are in their reference protonation form. Therefore, intrinsic $\mathrm{p} K_{\mathrm{a}}$ values and intrinsic midpoint potentials are only useful theoretical constructs rather than measurable quantities. To compute intrinsic $\mathrm{p} K_{\mathrm{a}}$ values and intrinsic midpoint potentials, $\mathrm{p} K_{\mathrm{a}}$ values and midpoint potentials of a model compounds are required. These values can be obtained either from experiment or from quantum chemical calculations. Sometimes only quantum chemical calculations are able to obtain the midpoint potentials for model compounds of prosthetic groups in proteins, because appropriate model compounds cannot be synthesized.

If only electrostatic contributions cause the difference between the protonation or reduction energies of a titratable group in a protein and in aqueous solution, the Poisson-Boltzmann equation provides a reasonable approximation of this energy difference. One contribution to the intrinsic $\mathrm{p} K_{\mathrm{a}}$ value of group $\mu \mathrm{p} K_{\mathrm{a}, u}^{\mathrm{intr}}$ is the $\mathrm{p} K_{\mathrm{a}}$ value of a proper model compound of the protonatable group $\mu$ in aqueous solution, $\mathrm{p} K_{\mathrm{a}, \mu}^{\text {model }}$. Transferring the protonatable group $\mu$ into a protein, in which all other protonatable groups are in their uncharged protonation or oxidation form, causes an energy shift. This energy shift can be separated into two contributions. The first energy contribution $\Delta \Delta G_{\mathrm{Born}}$ is a Born-energy-like term (eq 10), which arises from the interaction of the charges of the protonatable group with its reaction field. The second energy contribution $\Delta \Delta G_{\text {back }}$ arises from the interaction of the charges of the protonatable group with nontitrating background charges and with the charges of the uncharged form of all other titratable groups (eq 11).

$$
\begin{aligned}
\Delta \Delta G_{\text {Born }, \mu}^{\mathrm{prot}}=\frac{1}{2} \sum_{i=1}^{N_{Q, \mu}} Q_{\mu, i}^{\mathrm{h}}[ & \left.\phi_{p}\left(\mathbf{r}_{i} ; Q_{\mu}^{\mathrm{h}}\right)-\phi_{\mathrm{m}}\left(\mathbf{r}_{i} ; Q_{\mu}^{\mathrm{h}}\right)\right]- \\
& \frac{1}{2} \sum_{i=1}^{N_{Q, \mu}} Q_{\mu, i}^{\mathrm{d}}\left[\phi_{\mathrm{p}}\left(\mathbf{r}_{i} ; Q_{\mu}^{\mathrm{d}}\right)-\phi_{\mathrm{m}}\left(\mathbf{r}_{i} ; Q_{\mu}^{\mathrm{d}}\right)\right]
\end{aligned}
$$

$$
\begin{aligned}
\Delta \Delta G_{\mathrm{back}, \mu}^{\mathrm{prot}}=\sum_{i=1}^{N_{\mathrm{p}}} q_{i}\left[\phi_{p}\left(\mathbf{r}_{i} ; Q_{\mu}^{h}\right)-\phi_{p}\left(\mathbf{r}_{i} ; Q_{\mu}^{d}\right)\right]- \\
\sum_{i=1}^{N_{\mathrm{m}}} q_{i}\left[\phi_{\mathrm{m}}\left(\mathbf{r}_{i} ; Q_{\mu}^{\mathrm{h}}\right)-\phi_{\mathrm{m}}\left(\mathbf{r}_{i} ; Q_{\mu}^{\mathrm{d}}\right)\right]
\end{aligned}
$$

The summations in eq 10 run over the $N_{Q, \mu}$ atoms of group $\mu$ that have different charges in the protonated $(\mathrm{h})\left(Q_{i, u}^{\mathrm{h}}\right)$ and in the deprotonated (d) $\left(Q_{i, \mu}^{\mathrm{d}}\right)$ form. The first summation in eq 11 runs over the $N_{\mathrm{p}}$ charges of the protein that belong to atoms in nontitratable groups or to atoms of titratable groups (not to $\mu$ ) in their uncharged protonation form. The second summation in eq 11 runs over the $N_{\mathrm{m}}$ charges of atoms of the model compound that do not have different charges in the different protonation forms. The terms $\phi_{\mathrm{m}}\left(\mathbf{r}_{i}, Q_{\mu}^{\mathrm{h}}\right), \phi_{\mathrm{m}}\left(\mathbf{r}_{i}, Q_{\mu}^{\mathrm{d}}\right), \phi_{\mathrm{p}}\left(\mathbf{r}_{i}, Q_{\mu}^{\mathrm{h}}\right)$, and $\phi_{\mathrm{p}}\left(\mathbf{r}_{i}, Q_{\mu}^{\mathrm{d}}\right)$ denote the values of the electrostatic potential at the position $\mathbf{r}$ of the atom $i$. The electrostatic potential was obtained by solving the Poisson-Boltzmann equation numerically using the shape of either the protein (subscript p) or the model compound (subscript $\mathrm{m}$ ) as dielectric boundary and assigning the charges of the titratable group $\mu$ in either the protonated $\left(Q_{\mu}^{\mathrm{h}}\right)$ or the deprotonated $\left(Q_{\mu}^{\mathrm{d}}\right)$ form to the respective atoms. These two energy contributions and the $\mathrm{p} K_{\mathrm{a}}$ value of the model compound $\mathrm{p} K_{\mathrm{a}, \mu}^{\text {model }}$ are combined to the so-called intrinsic $\mathrm{p} K_{\mathrm{a}}$ value $\mathrm{p} K_{\mathrm{a}, \mu}^{\mathrm{intr}}$ (eq 12) of the residue.

$$
\mathrm{p} K \mathrm{a}_{\mathrm{a}, \mu}^{\mathrm{intr}}=\mathrm{p} K_{\mathrm{a}, \mu}^{\mathrm{model}}-\frac{1}{R T \ln 10}\left(\Delta \Delta G_{\mathrm{Born}, \mu}^{\mathrm{prot}}+\Delta \Delta G_{\mathrm{back}, \mu}^{\mathrm{prot}}\right)
$$

The intrinsic $\mathrm{p} K_{\mathrm{a}}$ value is the $\mathrm{p} K_{\mathrm{a}}$ value that this group would have if all other protonatable groups are in their reference protonation or oxidation form. I use the uncharged form as reference form. The interaction $W_{\mu \nu}$ between the two groups $\mu$ and $v$ in their charged form is defined in eq 13.

$$
W_{\mu \nu}=\sum_{i=1}^{N_{Q, u}}\left[Q_{\mu, i}^{\mathrm{h}}-Q_{\mu, i}^{\mathrm{d}}\right]\left[\phi_{\mathrm{p}}\left(\mathbf{r}_{i}, Q_{v}^{\mathrm{h}}\right)-\phi_{\mathrm{p}}\left(\mathbf{r}_{i}, Q_{v}^{\mathrm{d}}\right)\right]
$$

Similar to the definition of an intrinsic $\mathrm{p} K_{\mathrm{a}}$ value, I define an intrinsic midpoint potential $E_{\mathrm{intr}, \eta}^{\circ}$ for the redox-active group $\eta$. The intrinsic midpoint potential $E_{\text {intr, } \eta}^{\circ}$ is the standard redox potential that the redox-active group would have if all other titratable groups are in their respective reference form.

$$
E_{\mathrm{intr}, \eta}^{\circ}=E_{\mathrm{model}, \eta}^{\circ}+\frac{1}{F}\left(\Delta \Delta G_{\mathrm{Born}, \eta}^{\mathrm{redox}}+\Delta \Delta G_{\mathrm{back}, \eta}^{\mathrm{redox}}\right)
$$

The term $\Delta \Delta G_{\text {Born }}^{\text {redox }}$ arises from the interaction of the charges of the redox-active group $\eta$ with its reaction field. The term $\Delta \Delta G_{\mathrm{back}, \eta}^{\mathrm{redx}}$ arises from the interaction of the charges of the redox-active group $\eta$ with invariant background charges and with the charges of the reference form of all other titratable groups.

$$
\begin{gathered}
\Delta \Delta G_{\mathrm{Born}, \eta}^{\mathrm{red},}=\frac{1}{2} \sum_{i=1}^{N_{Q, \eta}} Q_{\eta, i}^{\mathrm{ox}}\left[\phi_{\mathrm{p}}\left(\mathbf{r}_{i} ; Q_{\eta}^{\mathrm{ox}}\right)-\phi_{\mathrm{m}}\left(\mathbf{r}_{i} ; Q_{\eta}^{\mathrm{ox}}\right)\right]- \\
\frac{1}{2} \sum_{i=1}^{N_{Q, \eta}} Q_{\eta, i}^{\mathrm{red}}\left[\phi_{\mathrm{p}}\left(\mathbf{r}_{i} ; Q_{\eta}^{\mathrm{red}}\right)-\phi_{\mathrm{m}}\left(\mathbf{r}_{i} ; Q_{\eta}^{\mathrm{red}}\right)\right] \\
\Delta \Delta G_{\mathrm{back}, \eta}^{\mathrm{redox}}=\sum_{i=1}^{N_{\mathrm{p}}} q_{i}\left[\phi_{\mathrm{p}}\left(\mathbf{r}_{i} ; Q_{\eta}^{\mathrm{ox}}\right)-\phi_{\mathrm{p}}\left(\mathbf{r}_{i} ; Q_{\eta}^{\mathrm{red}}\right)\right]- \\
\sum_{i=1}^{N_{\mathrm{m}}} q_{i}\left[\phi_{\mathrm{m}}\left(\mathbf{r}_{i} ; Q_{\eta}^{\mathrm{ox}}\right)-\phi_{\mathrm{m}}\left(\mathbf{r}_{i} ; Q_{\eta}^{\mathrm{red}}\right)\right]
\end{gathered}
$$

The meanings of the symbols in eqs 15 and 16 is analogous to the meanings in eqs 10 and 11 . 
The interaction $U_{\eta \chi}$ between the redox-active groups $\eta$ and $\chi$ is given by eq 17 .

$$
U_{\eta \chi}=\sum_{i=1}^{N_{Q, \eta}}\left[Q_{\eta, i}^{\mathrm{ox}}-Q_{\eta, i}^{\mathrm{red}}\right]\left[\phi_{p}\left(\mathbf{r}_{i}, Q_{\chi}^{\mathrm{ox}}\right)-\phi_{p}\left(\mathbf{r}_{\mathrm{i}}, Q_{\chi}^{\mathrm{red}}\right)\right]
$$

The interaction $V_{\eta \mu}$ between the redox active groups $\eta$ and protonatable group $\mu$ is given by eq 18 .

$$
\begin{aligned}
V_{\eta \mu} & =\sum_{i=1}^{N_{Q, \eta}}\left[Q_{\eta, i}^{\mathrm{ox}}-Q_{\eta, i}^{\mathrm{red}}\right]\left[\phi_{p}\left(r_{i}, Q_{\mu}^{h}\right)-\phi_{p}\left(\mathbf{r}_{i}, Q_{\mu}^{d}\right)\right] \\
& =\sum_{i=1}^{N_{Q, \mu}}\left[Q_{\mu, i}^{h}-Q_{\mu, i}^{d}\right]\left[\phi_{p}\left(\mathbf{r}_{i}, Q_{\eta}^{\mathrm{ox}}\right)-\phi_{p}\left(\mathbf{r}_{i}, Q_{\eta}^{\mathrm{red}}\right)\right]
\end{aligned}
$$

The energy of a particular protonation and redox state $n$, which is characterized by the state vector $\vec{x}^{n}=\left(x_{1}^{n}, x_{2}^{n}, \ldots, x_{N+K}^{n}\right)$, depends on the $\mathrm{pH}$ and the redox potential $E$ of the solution. It is given by eq 19 , where the value of $x_{\mu}^{n}$ is 1 or 0 depending on whether group $\mu$ is protonated (or reduced) or not; $q_{\mu}^{\circ}$ is the unitless formal charge of the deprotonated (reduced) form of group $\mu$.

$$
\begin{array}{r}
G_{n}=\sum_{\mu=1}^{N}\left(x_{\mu}^{n} R T \ln 10\left(\mathrm{pH}-\mathrm{p} K_{\mathrm{a}, u}^{\mathrm{intr}}\right)\right)+\frac{1}{2} \sum_{\mu=1}^{N} \sum_{\nu=1}^{N}\left(W_{\mu \nu}\left(x_{\mu}^{n}+q_{\mu}^{\circ}\right)\right. \\
\left.\left(x_{v}^{n}+q_{\nu}^{\circ}\right)\right)-\sum_{\eta=1}^{K}\left(x_{\eta}^{n} F\left(E-E_{\mathrm{intr}, \eta}^{\circ}\right)\right)+\frac{1}{2} \sum_{\eta=1}^{K} \sum_{\chi=1}^{K}\left(U_{\eta \chi}\left(x_{\eta}^{n}+q_{\eta}^{\circ}\right)\right. \\
\left.\left(x_{\chi}^{n}+q_{\chi}^{\circ}\right)\right)+\sum_{\eta=1}^{K} \sum_{\mu=1}^{N}\left(V_{\eta \mu}\left(x_{\eta}^{n}+q_{\eta}^{\circ}\right)\left(x_{\mu}^{n}+q_{\mu}^{\circ}\right)\right)
\end{array}
$$

In eq 19, all sums with $\mu$ or $v$ as index run over all protonatable residues; all sums with $\eta$ or $\chi$ as index run over all redox-active groups. The actual oxidation or protonation probabilities can be calculated, for instance, by the Monte Carlo titration method, ${ }^{8}$ the reduced site approximation, or hybrid statistical mechanics/ Tanford-Roxby method. ${ }^{23,24}$ Because I encountered serious sampling problems for some residues of cytochrome $c_{3}$ despite using the Monte Carlo titration method of Beroza et al. ${ }^{8}$ (unpublished results), I used a hybrid statistical mechanics/ Tanford-Roxby method.

Hybrid Statistical Mechanics/Tanford-Roxby Titration. I adapted the original hybrid statistical mechanics/TanfordRoxby algorithm ${ }^{24}$ to include the solution $\mathrm{pH}$ and redox potential. The algorithm combines a direct evaluation of the statistical average ${ }^{25}$ with the Tanford-Roxby approximation. ${ }^{5}$

In this approach, the protonation and oxidation probabilities of the $N+K$ titratable groups of a protein are calculated as follows. The $i_{s}$ protonatable groups and $j_{s}$ redox-active groups that interact with a particular group $s$ stronger than a given cutoff energy are treated exactly. The remaining $N-i_{s}$ and $K-j_{s}$ groups are considered by a Tanford-Roxby approximation. The energy of the protonation substate $n_{s}$ of the $\left(i_{s}+j_{s}\right)$ residues in the $k$ th iteration is given by eq 20

$$
\begin{aligned}
& G^{n_{s}}(k)= \sum_{\mu=1}^{i_{s}} x_{\mu}^{n_{s}} R T \ln 10\left(\mathrm{pH}-\mathrm{p} K_{\mathrm{a}, \mu}^{\mathrm{intr}}\right)+\frac{1}{2} \sum_{\mu=1}^{i_{s}} \sum_{\nu=1}^{i_{s}}\left(W _ { \eta v } \left(x_{\mu}^{n_{s}}+\right.\right. \\
&\left.\left.q_{\mu}^{\circ}\right)\left(x_{\nu}^{n_{s}}+q_{\nu}^{\circ}\right)\right) \\
&+\sum_{\mu=1}^{i_{s}} \sum_{\nu=i_{s}+1}^{N}\left(W_{\mu \nu}\left(x_{\mu}^{n_{s}}+q_{\mu}^{\circ}\right)\left(\left\langle x_{v}(k)\right\rangle+q_{\nu}^{\circ}\right)\right) \\
&-\sum_{\eta=1}^{j_{s}} x_{\eta}^{n_{s}} F\left(E-E_{\mathrm{intr}, \eta}^{\circ}\right)+\frac{1}{2} \sum_{\eta=1}^{j_{s}} \sum_{\chi=1}^{j_{s}}\left(U_{\eta \chi}\left(x_{\eta}^{n_{s}}+q_{\eta}^{\circ}\right) \times\right. \\
&+\sum_{\eta=1}^{j_{s}} \sum_{\chi=j_{s}+1}^{K}\left(U_{\eta \chi}\left(x_{\eta}^{n_{s}}+q_{\eta}^{\circ}\right)\left(\left\langle x_{\chi}(k)\right\rangle+q_{\chi}^{\circ}\right)\right) \\
&+\sum_{\mu=1}^{i_{s}} \sum_{\eta=j_{s}+1}^{K}\left(V_{\eta \mu}\left(x_{\mu}^{n_{s}}+q_{\mu}^{\circ}\right)\left(\left\langle x_{\eta}(k)\right\rangle+q_{\eta}^{\circ}\right)\right) \\
&+\sum_{\eta=1}^{j_{s}} \sum_{\mu=i_{s}+1}^{N}\left(V_{\eta \mu}\left(x_{\eta}^{n_{s}}+q_{\eta}^{\circ}\right)\left(\left\langle x_{\mu}(k)\right\rangle+q_{\mu}^{\circ}\right)\right)
\end{aligned}
$$

The average protonation $\left\langle x_{s}(k+1)\right\rangle$ of group $s$ in the $(k+1)$ th iteration is calculated from eq 21 .

$$
\left\langle x_{s}(k+1)\right\rangle=\frac{\sum_{n_{s}=1}^{2^{i_{s}+j_{s}}} x_{s}^{n_{s}} \exp \left(-G^{n_{s}}(k) / R T\right)}{\sum_{n_{s}=1}^{2^{i_{s}+j_{s}}} \exp \left(-G^{n_{s}}(k) / R T\right)}
$$

The same procedure is applied to all $N+K$ titratable groups and iterated until self-consistency is reached. The calculation must be repeated at each $\mathrm{pH}$ and solution redox potential in order to obtain a titration curve. In the first iteration step, the $\mathrm{p} K_{\mathrm{a}} / E^{\circ}$ values are assumed to be identical with the intrinsic $\mathrm{p} K_{\mathrm{a}} / E^{\circ}$ values. Note that for each group a different set of titratable groups will be treated exactly. A flowchart of the algorithm is depicted in Figure 2.

To achieve a more reliable convergence, I modified the criterion for defining the cluster of residues that are treated exactly during the iterations. All residues whose interaction energy with the central residue $s$ is larger than a certain threshold are included in the exactly treated cluster (first coupling limit). In addition, the residues that interact very strongly with the residues that couple very strongly to the central residue are included in the exactly treated cluster (second coupling limit).

Structures and Parameter. In the calculations, I used the structures of cytochrome $c_{3}$ from Desulfovibrio vulgaris Miyazaki (PDB code $2 \mathrm{CDV})^{26}$ having a resolution of $1.8 \AA$. All water molecules were deleted. Hydrogens were added with HBUILD ${ }^{27}$ in $\mathrm{CHARMM}^{28}$ and subsequently minimized using the AMBER 94 force field. ${ }^{29}$ The hemes are numbered according to the sequence order of the cysteinyl residues to which they are bound. This numbering is usually used in experimental studies but does not match the numbering in the PDB file. The numbering is also depicted in Figure 1. 


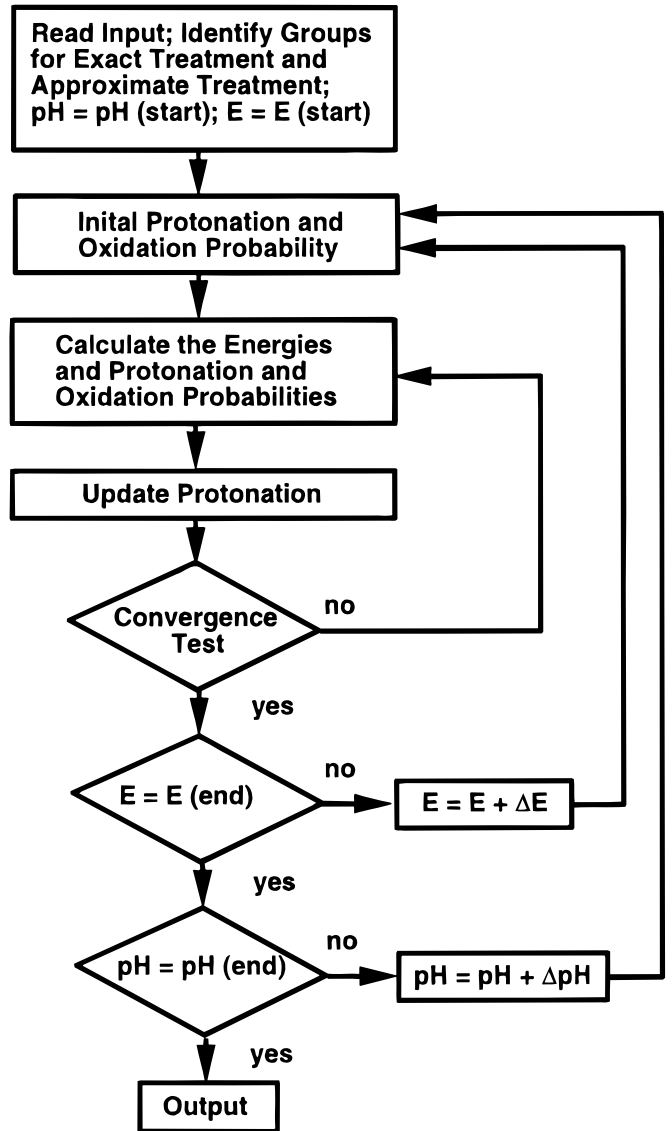

Figure 2. Flowchart of the hybrid statistical mechanics/TanfordRoxby approximation to calculate protonation and oxidation probabilities.

The intrinsic $\mathrm{p} K_{\mathrm{a}}$ and $E^{\circ}$ values were calculated by solving the Poisson-Boltzmann equation using the program MEAD. ${ }^{30,31}$ All aspartates, glutamates, histidines, lysines, arginines, tyrosines, the $\mathrm{N}$-terminus and $\mathrm{C}$-terminus of the protein, and the heme propionates were considered as protonatable groups. The hemes were considered as redox-active groups. The $\mathrm{p} K_{\mathrm{a}}$ values of the model compounds were taken from the literature. ${ }^{21,31}$ The redox potential of the bis-histidinyl heme model compound was set to $-220 \mathrm{mV} .{ }^{32}$ The atomic partial charges for most atoms were taken from the AMBER 94 force field. ${ }^{29}$ The partial charges of the hemes and the linked residues (two histidines modeled by methyl-imidazoles and two cysteines modeled by methyl-thiols) were obtained from a density functional calculation (functionals VWN ${ }^{33,34}$ and $\mathrm{PW}^{35}{ }^{35}$ ) using the ADF program package. ${ }^{36}$ The electrostatic potentials obtained from the density functional calculation were fitted using the CHELPG-algorithm ${ }^{37}$ combined with a singular value decomposition. ${ }^{38}$ The charges are given in Tables S1 and S2 in the Supporting Information. The ionic strength, the dielectric constant of the protein, and the dielectric constant of water were set to $0.1 \mathrm{M}, 4.0$, and 80.0, respectively. The electrostatic potential was calculated by focusing using two grids of $121 \times 121 \times 121$ grid points and grid spacings of of 1.0 and $0.25 \AA$. The first grid was centered on the protein or the model compound, the second grid was centered on the titratable group. These grids were used for the model compound as well as for the protein.

The actual titration was done with a hybrid statistical mechanics/Tanford-Roxby procedure as described above. If the interaction energy of a group with the central group $s$ was larger then $1.0 \mathrm{kcal} / \mathrm{mol}$, the group was treated exactly in the hybrid statistical mechanics/Tanford-Roxby procedure. In addition, all residues that couple stronger than $1.0 \mathrm{kcal} / \mathrm{mol}$ to residues that couple stronger than $1.0 \mathrm{kcal} / \mathrm{mol}$ to the central residue are treated exactly. A protonation or oxidation probability was assigned to all other residues. The hybrid statistical mechanics/ Tanford-Roxby procedure was iterated until the difference of the protonation or oxidation probability of each group was less then 0.01 between two subsequent steps of the iteration. Usually less than three iterations were required to meet this criterion. The protonation and oxidation probabilities were computed in the $\mathrm{pH}$ range from 0.0 to 14.0 in steps of $0.1 \mathrm{pH}$ units and in the solution redox potential in the range from -700 to $300 \mathrm{mV}$ in steps of $10 \mathrm{mV}$.

\section{Results and Discussions}

A Critical Analysis of Using the Terms Midpoint Potential and $\mathrm{p} K_{\mathrm{a}}$ Value for Protein Titration Curves. In proteins, the protonation or oxidation probability of usually more than one titratable group depends on the $\mathrm{pH}$ or redox potential of the solution. Consequently, the interaction between these titratable groups depends also on the $\mathrm{pH}$ or redox potential of the solution. Because of these interactions, titration curves of titratable groups in proteins can deviate considerably from sigmoidal Nernst or Henderson-Hasselbalch titration curves of isolated titratable groups. Thus it is sometimes impossible to assign a unique midpoint potential $E^{\circ}$ or $\mathrm{p} K_{\mathrm{a}}$ value to a specific titratable group. Therefore, the $\mathrm{pH}$ value at which the protonation probability of the protonatable group is 0.5 is often used instead to describe the titration behavior. Likewise, the solution redox potential $E$ at which the oxidation probability of the redox-active group is 0.5 is used to describe the titration behavior. These values are called $\mathrm{p} K_{1 / 2}$ and $E_{1 / 2}^{\circ}$ values, respectively. For isolated protonatable or redox-active groups, the $\mathrm{p} K_{1 / 2}$ and $E_{1 / 2}^{\circ}$ values coincide with real $\mathrm{p} K_{\mathrm{a}}$ and $E^{\circ}$ values. In molecules such as proteins in which titratable groups interact, titration curves have often a nonsigmoidal shape. Therefore, one cannot relate the $\mathrm{p} K_{1 / 2}$ or $E_{1 / 2}^{\circ}$ values directly to an energy difference. Thus, these values are not appropriate to discuss the $\mathrm{pH}$ or redox potential dependence of the energetics of catalytic mechanisms in proteins. Equations 22 and 23 define the $\mathrm{p} K_{\mathrm{a}}$ and $E^{\circ}$ values on the basis of the protonation or oxidation probabilities $\langle x\rangle$.

$$
\begin{aligned}
\mathrm{p} K_{\mathrm{a}} & =\mathrm{pH}+\frac{1}{\ln 10} \ln \frac{\langle x\rangle}{1-\langle x\rangle} \\
E^{\circ} & =E-\frac{R T}{F} \ln \frac{\langle x\rangle}{1-\langle x\rangle}
\end{aligned}
$$

These definitions are more appropriate than $\mathrm{p} K_{1 / 2}$ or $E_{1 / 2}^{\circ}$ values to discuss the energetics of proton or electron transfer reactions or enzymatic mechanisms, because they relate directly to energies by eqs 5 and 9 . According to these definitions, the $\mathrm{p} K_{\mathrm{a}}$ value depends explicitly on $\mathrm{pH}$ and the $E^{\circ}$ value depends explicitly on $E$. Both values depend also implicitly on $\mathrm{pH}$ and $E$, because the probability $\langle x\rangle$ depends on $\mathrm{pH}$ and $E$ (eqs 1 and 19). The direct and the indirect dependencies cancel for standard Henderson-Hasselbalch or Nernst titration curves yielding $\mathrm{pH}$ and $E$-independent $\mathrm{p} K_{\mathrm{a}}$ and $E^{\circ}$ values. Figure $3 \mathrm{a}$ depicts the calculated $\mathrm{pH}$-dependence of the protonation probability of a propionate D of heme III in cytochrome $c_{3}$ and a HendersonHasselbalch titration curve with the same $\mathrm{p} K_{1 / 2}$ value. Furthermore, the $\mathrm{pH}$ dependent $\mathrm{p} K_{\mathrm{a}}$ value calculated by eq 22 is shown. The $\mathrm{pH}$ dependent $\mathrm{p} K_{\mathrm{a}}$ value differs substantially from the $\mathrm{p} K_{1 / 2}$. Figure $3 \mathrm{~b}$ shows a similar plot for the solution redox potential dependence of the oxidation probability of heme I in cytochrome 
a) $\mathrm{pH}$ dependent $\mathrm{p} K_{a}$ value
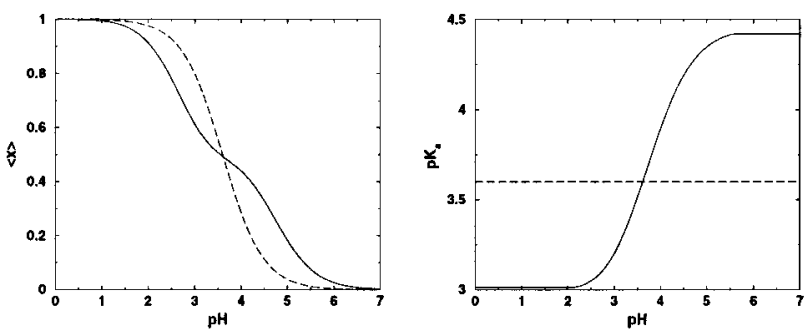

b)

$E$ dependent $E^{0}$ value
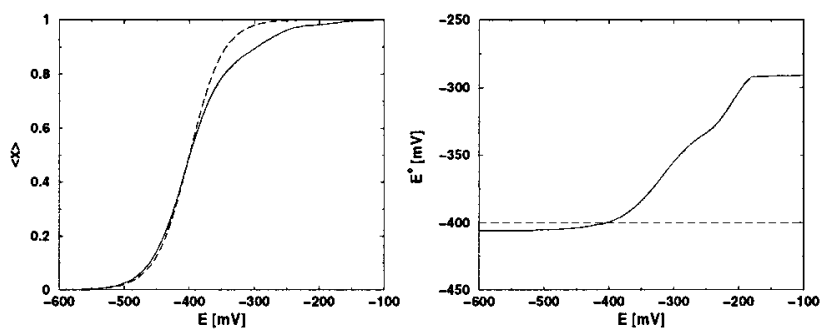

Figure 3. (a) Left: The solid line shows the $\mathrm{pH}$ dependent protonation probability of propionate $\mathrm{D}$ of heme $\mathrm{I}$ at $E=0 \mathrm{mV}$ computed by the hybrid statistical mechanics/Tanford-Roxby approach. This group shows a nonsigmoidal titration curve. For comparison, a HendersonHasselbalch titration curve (eq 3 ) with the same $\mathrm{p} K_{1 / 2}$ value is shown in the same graph by a dashed line. Right: The $\mathrm{pH}$ dependent $\mathrm{p} K_{\mathrm{a}}$ value (solid line) calculated by eq 22 can deviate significantly from the so-called $\mathrm{p} K_{1 / 2}$ value (dashed line). (b) Left: The solid line shows the solution redox potential dependent oxidation probability of heme III at $\mathrm{pH} 7.1$ computed by the hybrid statistical mechanics/TanfordRoxby approach. This group shows a nonsigmoidal titration curve. For comparison, a Nernst titration curve (eq 7) with the same $E_{1 / 2}^{\circ}$ value is shown in the same graph by a dashed line. Right: The solution redox potential dependent $E^{\circ}$ value (solid line) calculated by eq 23 can deviate significantly from the so-called $\mathrm{p} K_{1 / 2}$ value (dashed line). Both, the $\mathrm{p} K_{a}$ value and the $E^{\circ}$ value defined in eq 22 and 23 respectively can be related to an energy and are thus appropriate to discuss the energetics of $\mathrm{pH}$ and solution redox potential dependent reactions in proteins.

$c_{3}$ in comparison to a standard Nernst titration curve and the solution redox potential dependence of the $E^{\circ}$ value. The diagrams underline the importance to consider $\mathrm{p} K_{\mathrm{a}}$ and $E^{\circ}$ values that depend on $\mathrm{pH}$ and solution redox potential to discuss the energetics of biochemical reactions, because these values relate directly to the energetics of the protonation and redox reactions.

Also, experimentally determined titration curves do often show a non-Henderson-Hasselbalch or non-Nernst titration behavior. Therefore the experimentally determined $\mathrm{p} K_{1 / 2}$ values or $E_{1 / 2}^{\circ}$ are not appropriate for discussing the energetics of biochemical reactions. Rather $\mathrm{pH}$ and solution redox potential dependent $\mathrm{p} K_{\mathrm{a}}$ and $E^{\circ}$ values as defined in eqs 22 and 23 should be used for this purpose.

Oxidation Probabilities of the Hemes and Protonation Probabilities of Heme Propionates. Figure 4 shows the calculated oxidation probabilities of the hemes and protonation probabilities of the heme propionates and some amino acid residues of cytochrome $c_{3}$. However, all protonatable and redox active groups have been considered in the titration calculation. The probabilities are color coded as indicated by the scales next to the graphs. As one would expect, the midpoint potential of the hemes decreases with increasing $\mathrm{pH}$. The more the protein gets deprotonated the harder it gets to reduce the hemes. Likewise, the $\mathrm{p} K_{\mathrm{a}}$ values of the protonatable groups drop with increasing solution redox potential. The more hemes are reduced, the easier it becomes to protonate nearby titratable residues.

The oxidation probability of all hemes is $\mathrm{pH}$ dependent. The $\mathrm{pH}$ dependence is less pronounced for heme II and most
TABLE 1: Residues in Cytochrome $c_{3}$ from Desulfovibrio vulgaris Miyazaki that Have Interaction Energies Larger than $1.0 \mathrm{kcal} / \mathrm{mol}$ with the Hemes

\begin{tabular}{clc}
\hline \multirow{2}{*}{ heme } & \multicolumn{1}{c}{ interacting residue } & $\begin{array}{c}\text { interaction energy } \\
{[\mathrm{kcal} / \mathrm{mol}]}\end{array}$ \\
\hline heme I & heme II & 1.3 \\
& heme III & 1.4 \\
& propionate A (heme I) & 2.0 \\
& propionate D (heme I) & 3.6 \\
heme II & Tyr43 & 2.1 \\
& heme I & 1.3 \\
& propionate A (heme II) & 2.7 \\
& propionate D (heme II) & 1.8 \\
& propionate D (heme I) & 1.4 \\
heme III & Tyr65 & 1.3 \\
& His67 & 1.2 \\
& heme II & 1.3 \\
& heme I & 1.4 \\
& propionate A (heme III) & 3.4 \\
heme IV & propionate D (heme III) & 1.9 \\
& heme III & 1.3 \\
& propionate A (heme IV) & 2.4 \\
& propionate D (heme IV) & 3.9 \\
& Tyr65 & 2.4 \\
& Tyr66 & 2.4
\end{tabular}

pronounced for heme I. The $\mathrm{pH}$ dependence of the $E_{1 / 2}^{\circ}$ values and the average $E^{\circ}$ values computed from the oxidation probabilities using eq 23 are shown in Figure 5. The protonation probability of the propionate D of heme I depends strongly on the solution redox potential. Most likely this group is responsible for the experimentally observed redox Bohr effect. ${ }^{39-42}$ The computed $\Delta \mathrm{p} K_{\mathrm{a}}$ for the transition from the totally reduced to the totally oxidized form is about $4 \mathrm{pH}$ units. This value is larger than the experimental value of $2.1 \mathrm{p} K_{\mathrm{a}}$ units for cytochrome $c_{3}$ from Desulfovibrio vulgaris Hildenborough. ${ }^{43}$ There may be several reasons for the difference between the experimental and theoretical results. The sequence of cytochrome $c_{3}$ from Desulfovibrio vulgaris Hildenborough and from Desulfovibrio vulgaris Miyazaki are different, which can cause a different titration behavior. Furthermore, the structure of cytochrome $c_{3}$ undergoes changes upon reduction. ${ }^{44}$ These structural changes are not considered in the electrostatic calculation. The calculated $\mathrm{p} K_{\mathrm{a}}$ change occurs in the solution redox potential and $\mathrm{pH}$ range that was found experimentally and thus agrees with experimental data. The overestimation of $\mathrm{p} K_{\mathrm{a}}$ shifts is a known problem of the electrostatic titration method. ${ }^{21,31}$ The $\mathrm{p} K_{\mathrm{a}}$ value of propionate $\mathrm{D}$ from heme I shifts in two steps as can be seen in Figure 4. Thus, the first step of the $\mathrm{p} K_{\mathrm{a}}$ shift couples to the reduction of heme II, the second step to the reduction of heme I. The coupling of the $\mathrm{p} K_{\mathrm{a}}$ shift of propionate $\mathrm{D}$ of heme I to the reduction of heme II is also supported from the structure because this propionate is in proximity to heme II.

Table 1 lists the groups whose interaction energy with the heme redox active group is stronger than $1.0 \mathrm{kcal} / \mathrm{mol}$. The hemes interact most strongly with their own propionates. The interaction of heme II with propionate D of heme is larger, 1.4 $\mathrm{kcal} / \mathrm{mol}$, which is also a strong interaction. Propionate D of heme I is the titratable group that is responsible for the redox Bohr effect. Only a few amino acid residues interact strongly with the hemes. Thus it is unlikely that they are directly involved in the redox Bohr effect. Nevertheless, amino acid residues influence the redox Bohr effect by shifting the $\mathrm{p} K_{\mathrm{a}}$ of the heme propionates indirectly.

The experimentally determined midpoint potentials of the hemes of cytochrome $c_{3}$ from different sources range from -200 to $-400 \mathrm{mV}$. The actual values and the assignments to the hemes differ depending on the research group performing the 


\section{Oxidation Probabilities of the Hemes}
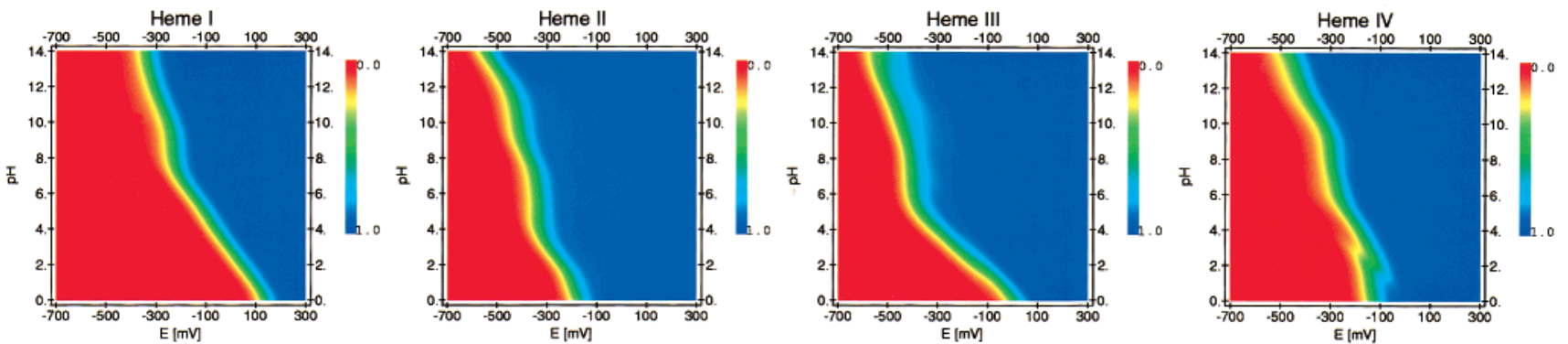

\section{Protonation Probabilities of the Heme Propionates}
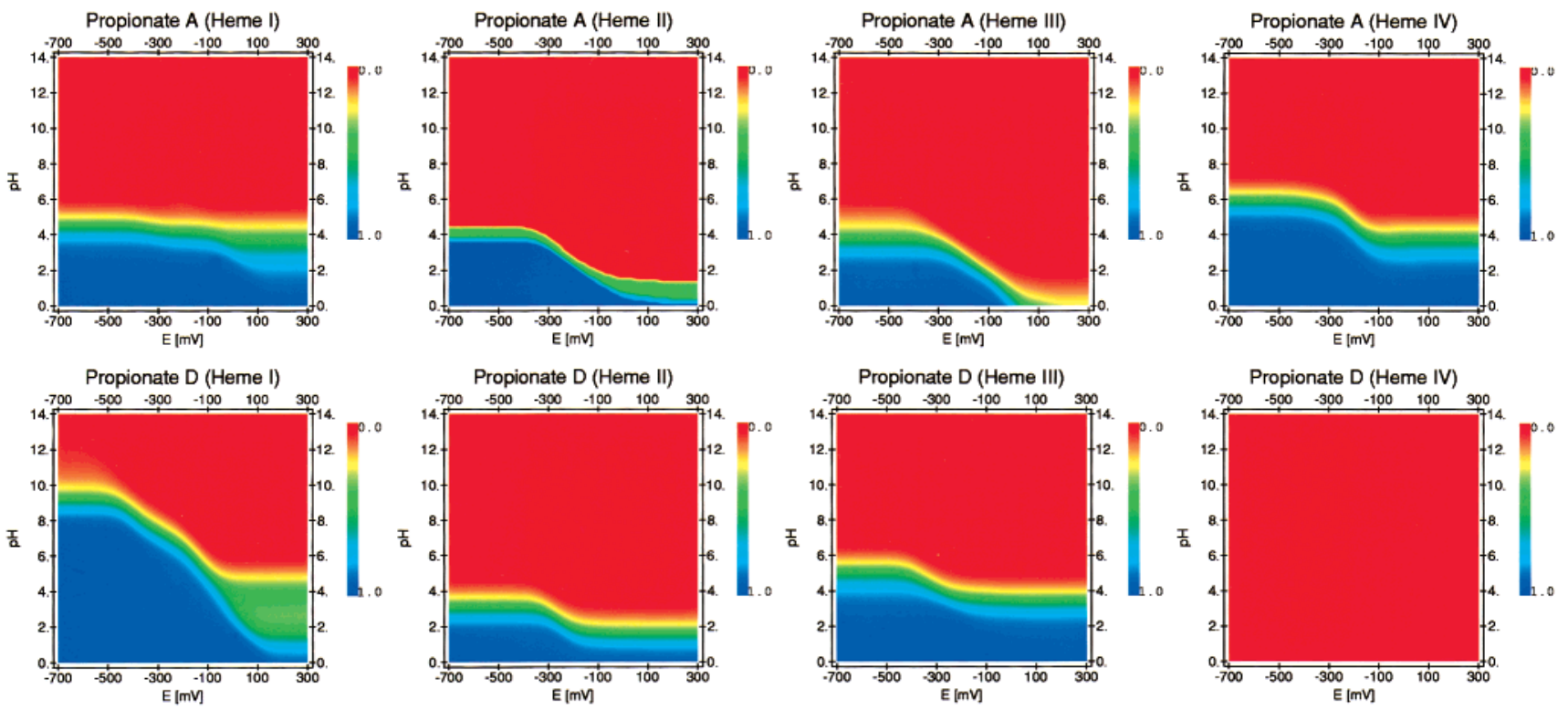

\section{Protonation Probabilities of Protonatable Residues}
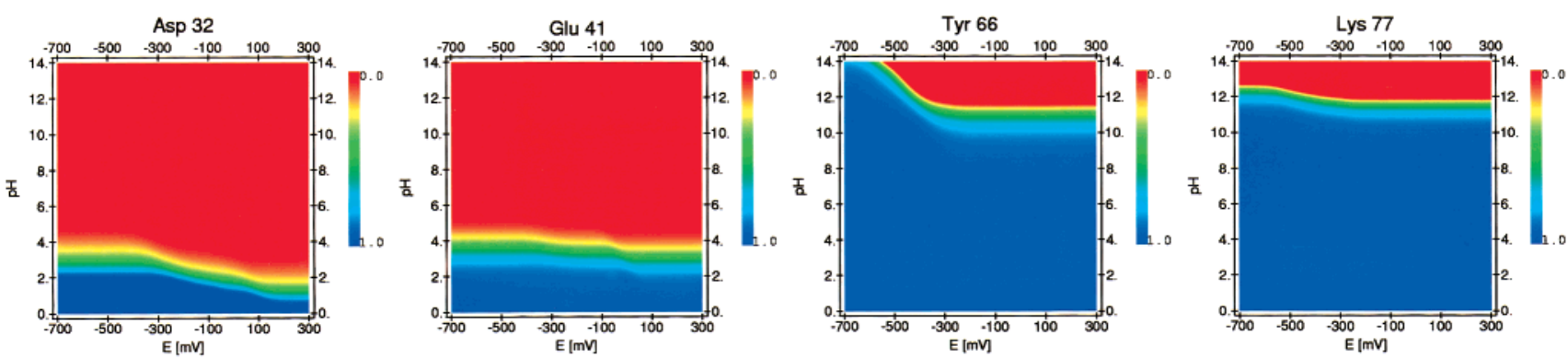

Figure 4. Calculated oxidation and protonation probabilities of the hemes, the heme propionates, and some amino acid residues of cytochrome $c_{3}$ from Desulfovibrio vulgaris Miyazaki. The probabilities are color coded as indicated by the scales next to the diagrams. The green color indicates when protonation or oxidation probability of the residues is about 0.5 , i.e., the middle of the green band indicates approximately the $\mathrm{pH}$ dependence of the $E^{\circ}$ value or the solution redox potential dependence of the $\mathrm{p} K_{\mathrm{a}}$ values. A detailed explanation of how to read these diagrams can be found in Figure S1 in the Supporting Information. The protonation probability of propionate D of heme I shows a strong dependence on the solution redox potential $E$. Most likely this group is responsible for the redox Bohr effect in cytochrome $c_{3}$. The $\mathrm{p} K_{\mathrm{a}} \mathrm{s}$ of most of the other heme propionates show also a dependence on the solution redox potential. This dependence is, however, much less pronounced. The $\mathrm{p} K_{\mathrm{a}} \mathrm{s}$ of amino acid residues do not show a strong dependence on the solution redox potential. All amino acid residues not shown in this figure show an even less pronounced redox potential dependence of their protonation probability. The interaction energy between the hemes and the four residues for which the protonation probability is shown in this figure is listed in Table S3 in the Supporting Information.

experiments, the method used to measure the midpoint potentials, and the method to assign the midpoint potentials. Akutsu and co-workers ${ }^{45}$ measured at $\mathrm{pH}=7.1$ midpoint potentials of $-260,-312,-327$, and $-369 \mathrm{mV}$ for cytochrome $c_{3}$ from Desulfovibrio vulgaris Miyazaki. These values agree reasonably well with the redox potentials determined by other groups and for other systems. ${ }^{46-48}$ The assignment of the midpoint potential to particular hemes is, however, very controversial. Different groups obtain different assignment for the cytochrome $c_{3}$ from Desulfovibrio vulgaris Miyazaki $i^{45,49,50}$ or from closely related 

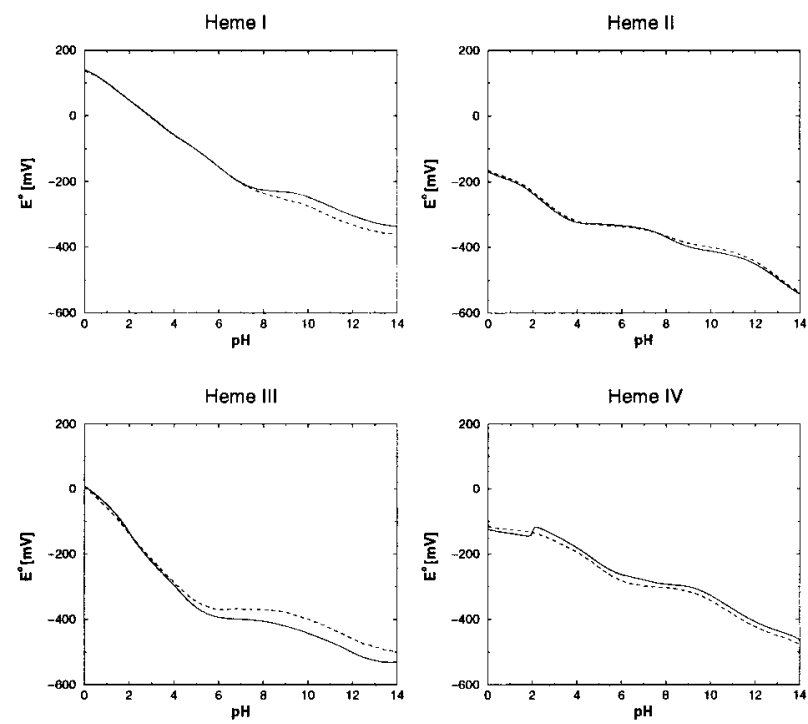

Figure 5. $\mathrm{pH}$ dependence of the $E_{1 / 2}^{\circ}$ value (solid line) and the average $E^{\circ}$ values (dashed line) computed from the oxidation probabilities using eq 23 . The $E^{\circ}$ values were included in the calculation of the average if the oxidation probabilities $\langle x\rangle$ were between 0.05 and 0.95 .

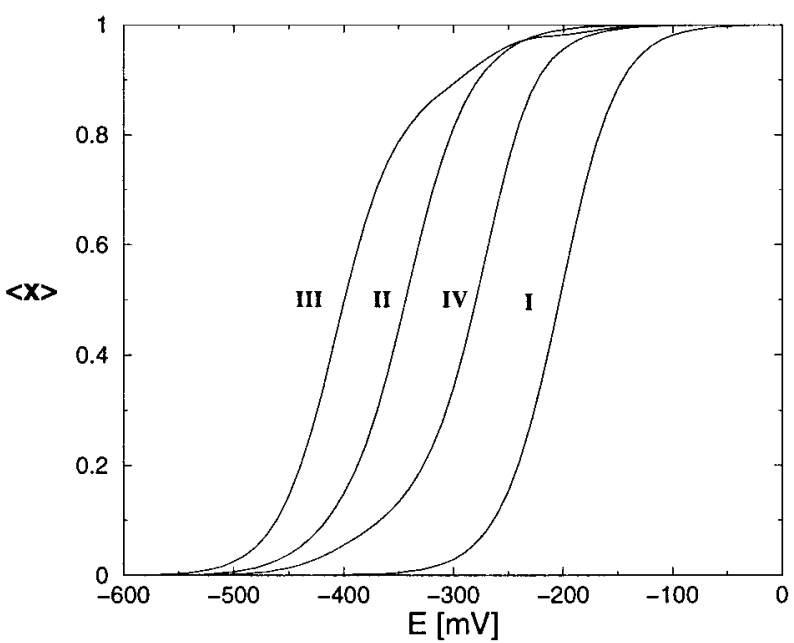

Figure 6. Oxidation probability of the different hemes in cytochrome $c_{3}$ from Desulfovibrio vulgaris Miyazaki at $\mathrm{pH}=7.1$. The hemes do not show a standard Nernst titration behavior because of the interaction with each other and with titratable groups in their vicinity.

species. ${ }^{46-48,51,52}$ Thus, the assignment of the order of the heme reduction is difficult because of conformational changes and protonations of some protonatable groups upon reduction as well as the presence of paramagnetic centers. In the theoretical calculations done in this study, I obtain as $E_{1 / 2}^{\circ}$ values -205 $\mathrm{mV}$ for heme I, $-280 \mathrm{mV}$ for heme IV, $-340 \mathrm{mV}$ for heme II, and $-400 \mathrm{mV}$ for heme III (Figure 6). However, it must be pointed out that the titration curves deviate from standard Nernst titration curves. This deviation is expected because of the interaction between the hemes and the interaction of the hemes with protonatable groups. Solution redox potential dependent $E^{\circ}$ values calculated by eq 23 range for heme I from -211 to $-202 \mathrm{mV}$, for heme IV from -340 to $275 \mathrm{mV}$, for heme II from -370 to $-325 \mathrm{mV}$, and for heme III from -405 to -300 $\mathrm{mV}$ (see also Figure 3 for heme III) at $\mathrm{pH}=7.1$. This variation of the $E^{\circ}$ values emphasizes again the importance for using solution redox potential dependent $E^{\circ}$ values.

Population of the Redox States. Because cytochrome $c_{3}$ binds four heme molecules, it can in principle adapt $2^{4}=16$

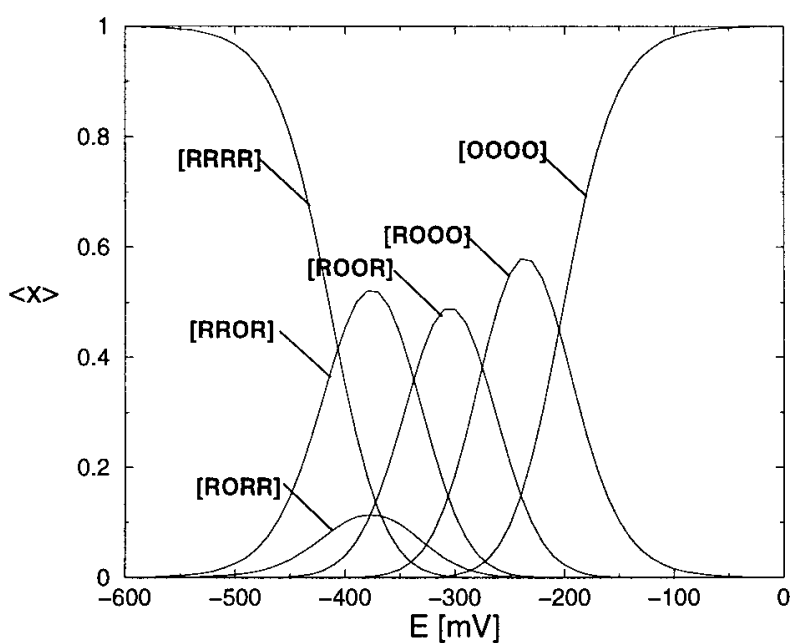

Figure 7. Population probabilities of the six different redox states of cytochrome $c_{3}$ from Desulfovibrio vulgaris Miyazaki at $\mathrm{pH}=7.1$ that have a population probabilities larger than 0.1 . The redox states are designated by a four letter code: [RORR] describes, for instance, that heme II is oxidized $(\mathrm{O})$ and all other three hemes are reduced $(\mathrm{R})$.

redox states and 32 microscopic redox potentials can be defined. For energetic reasons, not all redox states may, however, been populated to an significant extent. Figure 7 shows the calculated solution redox potential dependent population probability of all redox state at $\mathrm{pH}=7.1$ whose population probability is larger than 0.1 . Only 6 of the 16 states are significantly populated according to the calculation. Some of the other redox states are virtually unpopulated. If this behavior reflects reality, not all of the 32 microscopic redox potentials would be measurable.

\section{Conclusion}

In this study, I present a method to compute protonation and oxidation probabilities depending on the solution redox potential and $\mathrm{pH}$. With this method it is possible to investigate the electrostatic coupling of redox and protonation reactions in proteins. Such couplings are important for proton pumping mechanisms in membrane-bound respiratory and photosynthetic protein complexes. The theoretical method can pinpoint which protonatable groups are responsible for the $\mathrm{pH}$ dependent behavior. Amino acids which were identified to influence the redox potential can then be mutated and the effects of such mutations can be studied experimentally as well as theoretically. Such computations can therefore also help to interpret experimental results and may guide to mutagenesis and other experiments.

Acknowledgment. I am grateful for a Postdoctoral Fellowship of the Deutsche Forschungsgemeinschaft (UL 174/1-1). Furthermore, this work was supported by NIH grant GM 39914. I thank Prof. Donald Bashford for providing his program MEAD and Prof. Donald Bashford, Prof. David A. Case, Prof. ErnstWalter Knapp, Prof. Louis Noodleman, and Björn Rabenstein for helpful discussions.

Supporting Information Available: Three tables and one figure. Table S1: partial charges of the heme and the histidine ligands that are different in the oxidized and reduced state. Table S2: partial charges of the heme and the histidine ligands that are identical in the oxidized and reduced state. Table S3: interaction of the hemes and the heme propionates with a few selected residues. Figures S1: A schematic explanation of how 
to read the diagrams in Figure 4. This material is available free of charge via the Internet at http://pubs.acs.org.

\section{References and Notes}

(1) Cramer, W. A.; Knaff, D. B. Energy Transduction in Biological Membranes; Springer: New York, 1991.

(2) Ullmann, G. M. Charge-Transfer Properties of Photosynthetic and Respiratory Proteins. In Supramolecular Photo-sensitive and Electroactive Material; Nalwa, H. S., Ed.; Academic Press: New York, in press.

(3) Bashford, D.; Karplus, M. Biochemistry 1990, 29, 10219-10225. 5347.

(4) Tanford, C.; Kirkwood, J. G. J. Am. Chem. Soc. 1957, 79, 5333-

(5) Tanford, C.; Roxby, R. Biochemistry 1972, 11, 2192-2198.

(6) Antosiewicz, J.; McCammon, J. A.; Gilson, M. K. J. Mol. Biol. 1994, 238, 415-436.

(7) Juffer, A. H.; Argos, P.; Vogel, H. J. J. Phys. Chem. B 1997, 101, $7664-7673$

(8) Beroza, P.; Fredkin, D. R.; Okamura, M. Y.; Feher, G. Proc. Natl. Acad. Sci. U.S.A. 1991, 88, 5804-5808.

(9) Beroza, P.; Case, D. A. J. Phys. Chem. 1996, 100, 20156-20163.

(10) Kannt, A.; Lancaster, C. R. D.; Michel, H. Biophys. J. 1998, 74, $708-721$.

(11) Lancaster, C. R.; Michel, H.; Honig, B.; Gunner, M. R. Biophys. J. 1996, 70, 2469-2492.

(12) Sham, Y. Y.; Chu, Z. T.; Warshel, A. J. Phys. Chem. B 1997, 101, $4458-4472$.

(13) Mehler, E. L. J. Phys. Chem. 1996, 100, 16006-16018.

(14) Demchuck, E.; Wade, R. C. J. Phys. Chem. 1996, 100, $17373-$ 17387.

(15) Muegge, I.; Apostolakis, J.; Ermler, U.; Fritsch, G.; Lubitz, W.; Knapp, E. W. Biochemistry 1996, 35, 8359-8370.

(16) Ullmann, G. M.; Muegge, I.; Knapp, E. W. Shifts of the Special Pair Redox Potential of Mutants of Rhodobacter sphaeroides Calculated with Delphi and Charmm Energy Functions. In The Reaction Centers of Photosynthetic Bacteria. Structure and Dynamics; Michel-Beyerle, E. M., Ed.; Springer: Berlin, 1996; pp 143-155.

(17) Beroza, P.; Fredkin, D. R.; Okamura, M. Y.; Feher, G. Biophys. J. $1995,68,2233-2250$.

(18) Rabenstein, B.; Ullmann, G. M.; Knapp, E. W. Biochemistry 1998, 37, 2488-2495.

(19) Rabenstein, B.; Ullmann, G. M.; Knapp, E. W. Eur. Biophys. J. 1998, $27,628-637$

(20) Rabenstein, B.; Ullmann, G. M.; Knapp, E. W. Biochemistry 2000, 39 , in press. 551

(21) Ullmann, G. M.; Knapp, E. W. Eur. Biophys. J. 1999, 28, 533-

(22) Baptista, A. M.; Martel, P. J.; Soares, C. M. Biophys. J. 1999, 76, $2978-2998$

(23) Gilson, M. K. Proteins 1993, 15, 266-282.

(24) Yang, A.-S.; Gunner, M. R.; Sompogna, R.; Honig, B. Proteins 1993, 15, 252-265.

(25) Bashford, D.; Karplus, M. J. Phys. Chem. 1991, 95, 9557-9561.
(26) Higuchi, Y.; Kusunoki, M.; Matsuura, N.; Yasuoka, N.; Kakudo, M. J. Mol. Biol. 1984, 172, 109-139.

(27) Brünger, A. T.; Karplus, M. Proteins 1988, 4, 148-156.

(28) Brooks, B. R.; Bruccoleri, R. E.; Olafson, B. D.; States, D. J.; Swaminathan, S.; Karplus, M. J. Comput. Chem. 1983, 4, 187-217.

(29) Pearlman, D.; Case, D.; Caldwell, J.; Ross, W.; Cheatham, T.; DeBolt, S.; Ferguson, D.; Seibel, G.; Kollman, P. Comput. Phys. Commun. 1995, 91, 1-41

(30) Bashford, D.; Gerwert, K. J. Mol. Biol. 1992, 224, 473-486.

(31) Bashford, D.; Case, D. A.; Dalvit, C.; Tennant, L.; Wright, P. E. Biochemistry 1993, 32, 8045-8056.

(32) Wilson, G. S. Bioelectrochem. Bioenerg. 1983, 1, 172-179.

(33) Vosko, S. H.; Wilk, L.; Nusair, M. Can. J. Phys. 1980, 1200, 58.

(34) Stoll, H.; Pavlidou, C. M. E.; Preuss, H. Theor. Chim. Acta 1978, 49,143

(35) Perdew, P.; Chevary, J. A.; Vosko, S. H.; Jackson, K. A.; Pederson,

M. R.; Singh, D. J.; Fiolhais, C. Phys. Rev. B 1992, 46, 6671.

(36) Guerra, C. F.; Snijders, J. G.; te Velde, G.; Baerends, E. J. Theor Chem. Acc. 1998, 99, 391-403.

(37) Breneman, C. N.; Wiberg, K. B. J. Comput. Chem. 1990, 11, 361373.

(38) Chen, J. L.; Noodleman, L.; Case, D.; Bashford, D. J. Phys. Chem. 1994, 98, 11059-11068.

(39) Turner, D. L.; Salgueiro, C.; Catarino, T.; LeGall, J.; Xavier, A V. Biochim. Biophys. Acta 1994, 1187, 232-235.

(40) Louro, R. O.; Catarino, T.; Salgueiro, C. A.; LeGall, J.; Xavier, A. V. J. Biol. Inorg. Chem. 1996, 1, 34-38.

(41) Park, J.; Ohmura, T.; Kano, K.; Sagara, T.; Niki, K.; Kyogoku, Y.; Akutsu, H. Biochim. Biophys. Acta 1996, 1293, 45-54.

(42) Salgueiro, C. A.; Turner, D. L.; Xavier, A. V. Eur. J. Biochem. 1997, 244, 721-734.

(43) Saraiva, L. M.; Salgueiro, C.; da Costa, P. N.; Messias, A. C.; LeGall, J.; van Dongen, W. M.; Xavier, A. V. Biochemistry 1998, 37 $12160-12165$

(44) Kazanskaya, I.; Lexa, D.; Bruschi, M.; Chottard, G. Biochemistry 1996, $35,13411-13418$

(45) Fan, K.; Niki, K.; Kyogoku, Y.; Akutsu, H. Biochemistry 1990, 29, $2257-2263$

(46) Gayda, J. P.; Benosman, H.; Bertrand, P.; More, C.; Asso, M. Eur. J. Biochem. 1988, 177, 199-206.

(47) Guigliarelli, B.; Bertrand, P.; More, C.; Haser, R.; Gayda, J. P. J. Mol. Biol. 1990, 216, 161-166.

(48) Morais, J.; N., P.; Palma; Frazão, C.; Caldeira, J.; LeGall, J.; Moura I.; Moura, J. J.; Carrondo, M. A. Biochemistry 1995, 34, 12830-12841.

(49) Gayda, J. P.; Yagi, T.; Benosman, H.; Bertrand, P. FEBS Lett. 1987, 217, 57-61.

(50) Park, J.-S.; Kano, K.; Niki, K.; Akutsu, H. FEBS Lett. 1991, 285 , 149-151.

(51) Dolla, A.; Cambillau, C.; Bianco, P.; Haladjian, J.; Bruschi, M. Biochem. Biophys. Res. Commun. 1987, 147, 818-823.

(52) Louro, R. O.; Pacheco, I.; Turner, D. L.; LeGall, J.; Xavier, A. V. FEBS Lett. 1996, 390, 59-62. 